\title{
NOTES
}

\section{A RECOVERED HARRY STAFFORD LETTER TO WALT WHITMAN}

In recent years Whitman's relationship with Harry Stafford has come under careful scrutiny. Whitman had met the eighteen-year-old Stafford in 1876 while he was working in a printing office in Camden. Stafford proved to be yet another of the "invariably semiliterate, emotionally insecure [young men], ... desirous of establishing a dependent relationship with an older man" that Whitman had always been attracted to. "This was the emotional experience of the period between 1876 and 1885 - the last of the intense 'Calamus' friendships."

Most of Stafford's letters to Whitman, from 1877 to 1884, are in the Feinberg Collection. One, for 1880, is in the John Rylands Library, University of Manchester, England, and another, for 1892, is printed in Charley Shively's Calamus Lovers. ${ }^{2}$ To these can now be added an uncatalogued Harry Stafford letter to Whitman in the Harned-Whitman collection, "Drift Sands" Folder (L. C. 41), Cont. no. 1, Manuscript Division, Library of Congress. The letter is found among twenty separate holograph sheets and scraps containing heavily revised trial titles and a few trial lines. They strongly appear to have been intended either for a separate cluster of poems for a forthcoming edition of Leaves of Grass (i. e. the 1881, sixth edition), or possibly for separate publication in a small volume, independent of Leaves. ${ }^{3}$ In any event, Whitman was to collect his post-1881 poems in the "1st Annex, Sands at Seventy," where he finally salvaged the dominant "Sands" image of the "Drift Sands" Folder. "Sands at Seventy" was included in November Boughs (1888). This and the later "2d Annex, Good-Bye my Fancy" (1891), were incorporated into the final 1891-92 impression of the 1881 edition, the so-called "Death-Bed" Edition.

The heavily revised "Drift Sands" holographs in the Harned Collection are numbered 90-109. It was Whitman's habit to use the clear verso of whatever used sheet of paper or scrap was handy for trial titles and lines for his poetry. Among the used holograph sheets in the "Drift Sands" Folder are letters that had been sent to Whitman. The undated Stafford letter appears on sheet no. 104. It is written in pencil in Stafford's usual rough, scratchy hand, ${ }^{4}$ on faded salmon-colored paper, with the left, right, and bottom edges flaked and the top margin trimmed, and is approximately $71 / 8$ " $\times 57 / 8$ ". Whitman drew a cancelling stroke through it with a heavy blue pencil.

The letter reads:

Dear Walt was just about 15 minutes to 5 late for the train which I laid out to gou on, So I came around, thinking perhaps to find you in but on arriving here, 6 I find you are not so I thought I would write a line showing you that I came.

Yours with Love Harry

It is difficult to pinpoint the date of the letter, but it appears to have been written around 1880 or so. On its cancelled verso Whitman wrote out in heavy blue pencil, with later corrections in black ink, what appear to have been trial titles for a cluster of poems. Before revision the trial titles read: 


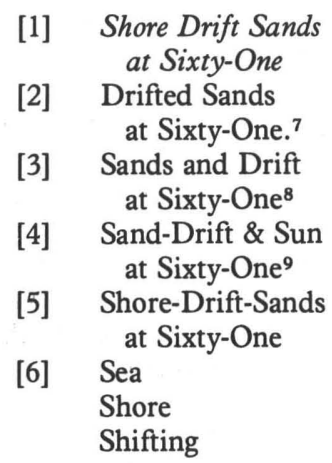

The " 60 " and " 61 " dates reoccur in the "Drift Sand" sheets, with some later mended to accommodate the passing years. For example, in no. 106, Whitman wrote in heavy blue pencil "Sands on the Shores of 60 \& after." In no. 107 he had initially written out in heavy blue pencil "Sands on the Shores of my 61st Year." Later, in blue pencil, he mended " 61 st" to "64th." He appears at this point to have queried the revised title, only to add the date of the revision with a fresh trial title: "April 13, '82No-I think I like better Sands at 64.”

The initial "Shore Drift Sands|at Sixty-One" trial title and its variations which Whitman wrote out on the verso of the Stafford letter ordinarily would support a reading of 1880 or so for this letter. However, internal evidence in this instance might well point only to a more or less approximate date. For example, at the time he wrote the above "Sands at 64" entry, on 13 April 1882, he was a few weeks shy of his sixty-third birthday. ${ }^{10}$

The City College, New York

ARTHUR GOLDEN

\section{NOTES}

1 Correspondence, ed. Edwin H. Miller (New York: New York University Press, 1964), 3:3-4, 9. Miller offers a perceptive account (2-9) of this alternately stormy and intimate relationship. Ed Folsom's concise review of the relevant scholarship on the Whitman-Stafford relationship accompanies the publication of "An Unknown Photograph of Whitman and Stafford," Walt Whitman Quarterly Review (Spring 1986), 3:51-52 and back cover, which pictures a ring given Stafford by Whitman. Calamus Lovers: Walt Whitman's Working Class Camerados, ed. Charley Shively (San Francisco: Gay Sunshine Press, 1987), devotes a chapter to the Whitman-Stafford relationship (pp. [137]-49) and for the first time makes available Stafford's letters to Whitman (pp. 150-71). Shively offers some interesting observations on the relationship but also often belabors the obvious and confuses conjecture with certainty. Regrettably, his editing of the important Stafford letters to Whitman leaves much to be desired, if one is to judge from a random comparison of the first letter to turn up in the "Harry Stafford General Correspondence" Folder, Feinberg Collection, Manuscript Division, Library of Congress (DCN 198; DCN 204), Cont. no. 16, with Shively's transcription of this 18 January 1878 letter, in which Stafford asks Whitman to "please foregive me [Stafford's spelling here and throughout]." 
In this four-page letter, much of 11. 1-4 on pp. 1 and 4 and 11. 4-7 on pp. 2-3 are badly obscured or obliterated by heavy water stains. (The bottom margins are stained but readable.) Shively omits any mention of the stains. Instead, apparently he substituted an ellipsis for the unreadable parts of the text. In the absence of an editorial note to the contrary, one would normally take the ellipsis to signify the omission of some trivial repetition or phrase but here, peculiarly, it seems to denote his inability to read the stained text. The unstained parts of the letter are in a clear hand. (See n. 4, below.)

Apparently Shively failed to utilize the excellent resources of the Manuscript Division in an attempt to help him recover parts of the stained letter. (For many courtesies I am indebted to Charles Kelly, Manuscript Division, and Karen Garlick, Paper Conservator and Liaison to the Manuscript Division, who was able to recover most of the water-stained text in question by the process of "ultraviolet wave radiation.")

Thus, in the stained parts of the text the normalized "January 18, 1878." should read "January 18th 1878"; "Dear Walt" should read "Dear friend Walt:"; in 11. 8-9, Shively reads "stoped to see you until I [was prevented] you know that I"; the recovered passage reads "stoped to [unreadable] you but [unreadable] until I heard from you. Do you know that I"; in 11. 16-17 Shively reads "much. I have [found a girlfriend] and, that is to say, she is a good and true friend"; the recovered passage reads "much. I have but one friend left [unreadable] and that is [unreadable], she is a good and true friend"; and in 11. 23-24 Shively reads "today . . . They have got"; the recovered passage reads "to-day: the little Irish-/man [line-break] that was here this winter! you remember him.) They have got."

Nor do things get any better in the unstained parts of the letter. Shively properly makes much of Whitman's attraction to semiliterate young men, but for some reason he proceeds to obscure in this transcription the full flavor of Stafford's text by normalizing most of the misspellings in the unstained parts of the letter. While Shively retains some of Stafford's misspellings, i.e. "stoped," "folkes," "myselfe," "deviding," elsewhere he silently normalizes "sattesfied," "Herbret" (for Herbert Gilchrist, Anne Gilchrist's son), "togeather," "comeing," "fore gotten," and "gon." Shively also offers "fy[r]st rait," but this clearly reads as the single word "firstrait." The point of the top oval curve of the capital "I" immediately below it touched the bottom of the " $r$," which apparently Shively then read as a " $y$ " and added an unnecessary editorially bracketed "r." To conclude matters, in 1.5 a comma follows "you," in 1.28 "that" should read "this," in 1.29 "institute" should be capitalized, and in 1.30 a comma follows "letter" and there is no comma following "adieu." The two Stafford letters to Whitman that immediately follow the 18 January 1878 letter, those of 24 January 1878 and 26 March 1878, are also water-stained. Finally in separate headnotes Shively alerts the reader to this fact. Nevertheless, as in the 18 January letter, his transcriptions of them again contain ellipses and bracketed editorial interpolations. These must pass without comment as I had other matters to attend to.

\section{See "A Calendar of Letters Written to Whitman," Correspondence, 3:441 et passim.}

3 The latter possibility, however tentative it might have been at this stage, is supported by holograph no. 96 . Here on a split envelope, approximately $13 / 16 " \times 39 / 16$ ", he drew a rectangular emblem, initially carefully blocked-out in pencil and then traced-over in heavy black ink, with later emendations in blue pencil. The emblem reads "SANDS on the Shores"(written diagonally and underscored) "of 61 \& '2" (a looped ornamental stroke curves beneath it), "By Walt Whitman" (a short ornamental rule precedes "By"). In blue pencil Whitman mended the " 1 " and "'2" to " 4 " and "'5." Such a volume was never published.

4 Stafford had tried to improve his handwriting. In an undated letter he indicated that he was practicing his handwriting and asked Whitman whether he could get him "a coppy book." The water-stained 18 January 1878 letter, written in black ink on lined paper, appears to have been carefully copied from some intermediate draft. The Harned Collection Stafford letter was written on the spot.

5 Initially "to" read "too," with the second "o" cancelled. 
6 I.e. 431 Stevens Street, Camden, New Jersey.

7 In black ink the queried: "? five" interlined over the uncancelled "One".

8 In heavy black ink Whitman traced over the initial blue pencil entry, querying the new numbers: "Sands and Drift|at Sixty-?four/?five."

9 In blue pencil "two" mended over the initial "One."

10 If 1880 , Stafford's letter might have been written between the first week of January, when Whitman had returned from a trip to the West, to early June, when he again left Camden to visit Dr. Maurice Bucke in London, Ontario, and other places of interest, or from the beginning of October on, when he had returned to Camden from his travels. See Correspondence, 3:173, 180, et passim.

\section{ANOTHER HARRY STAFFORD LETTER}

In his above note on a recently discovered Harry Stafford letter to Whitman, Arthur Golden mentions another Stafford letter-in addition to the one that he printed - that did not appear in the collection of letters from Stafford to Whitman in Charley Shively's Calamus Lovers (San Francisco: Gay Sunshine, 1987), pp. 149171. This missing Stafford letter is in the Charles Sixsmith Collection at the John Rylands University Library of Manchester, England. ${ }^{1}$ It is written on a small card, and is in an envelope addressed, in Whitman's own hand, to "Walt Whitman London Ontario Canada" - he sent self-addressed envelopes to Harry and his family in order to encourage them to write while he was on his Canadian trip. ${ }^{2}$ The envelope is postmarked 17 July 1880 at Kirkwood, New Jersey. The letter actually consists of two messages, one written on top of the other in a palimpsest, with parts of the first message rendered unreadable by the second. The first message is as follows:

All are well at our place [unreadable word] received your papers \& letter in due issue. How long do you intend to stay in London and when do you think of returning to Camden? I must s[rest of word unreadable] on the day after you left was very [unreadable word]-surprised at [unreadable word] in departure. Hope to receive a letter from you soon. From your affectionate son, H. L. Stafford

Written across this message is the following, obviously added by Harry after he received another letter from Whitman:

Dear Walt-

Your postal received was glad to hear from you and learn you were well and enjoying yourself but sorry to hear that you were sick at last accounts. Your dear boy,

Harry

Although the initial message is tantalizingly unreadable in key parts, the letter is important for the suggestions of Stafford's emotional reaction to Whitman's departure. 